\begin{tabular}{c} 
\\
A NOVA RAZÃO DO MUNDO \\
ENSAIO SOBRE A SOCIEDADE NEOLIBERAL \\
\hline THE NEW WAY OF THE WORLD \\
ON NEOLIBERAL SOCIETY \\
LA NUEVA RAZÓN DEL MUNDO \\
ENSAYO SOBRE LA SOCIEDAD NEOLIBERAL
\end{tabular}

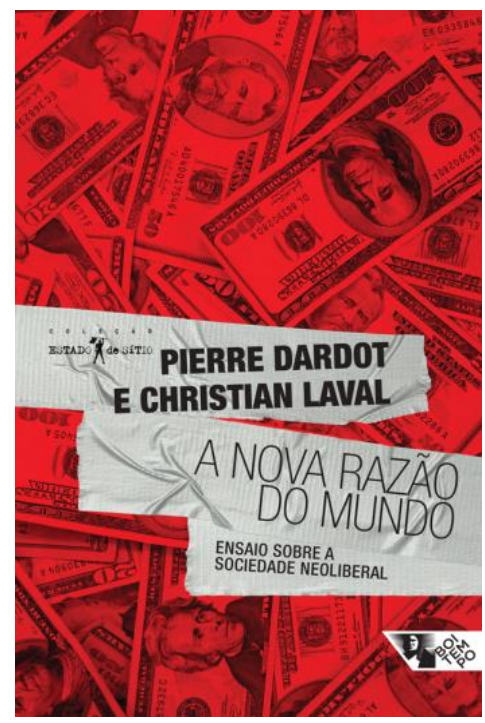

DARDOT, Pierre; LAVAL, Christian. A nova razão do mundo: ensaio sobre a sociedade neoliberal. Tradução Mariana Echalar. 1. ed. São Paulo: Boitempo, 2016.

Aline Bettiolo dos Santos ${ }^{1}$

O livro A nova razão do mundo: ensaio sobre a sociedade neoliberal, lançado em 2016 pela Editora Boitempo - SP, traz um debate sobre o que é o neoliberalismo, sua gênese, seus aspectos e sua influência não apenas sobre o Estado e a sociedade, mas também sobre os sujeitos, de modo que esse debate destaca ainda, como "a nova razão do mundo" foi se consolidando ao longo de um processo histórico.

A obra de Pierre Dardot e Christian Laval contém nove capítulos distribuídos em duas partes, sendo que na primeira, os autores exploram a "refundação intelectual" e anotam como fraturas no liberalismo clássico, a partir de meados do século XIX, levaram a repensar os dogmas do laissez-faire. Assim, dois grupos divergentes surgiram e foram favoráveis a uma maior ou a uma menor renovação no sistema capitalista, o que faz com que um desses grupos simpatizasse com maiores transformações dos dogmas liberais, enquanto que o outro se mantinha mais conservador em relação às mudanças dos princípios do liberalismo.

Já na segunda parte, os autores ponderam acerca da "nova racionalidade", destacando um

${ }^{1}$ Submetido em: 08/02/2018 - Aceito em: 27/02/2018 - Publicado em: 17/07/2018.

\begin{tabular}{|l|c|c|c|c|c|}
\hline (C) Rev. Inter. Educ. Sup. & Campinas, SP & v.4 & n.3 & p.761-764 & set./dez. 2018 \\
\hline
\end{tabular}


processo no qual o neoliberalismo veio ganhando força e por conseguinte, imprimiu suas marcas no governo, que passou a expressar cada vez mais seus traços empresariais, assim como nos sujeitos, "fabricados" com excelência de acordo com a razão neoliberal.

Considerando que ao haver queda nas taxas de lucro há "mutações" no capitalismo, isto é, ele se reconfigura, Dardot e Laval discorrem no primeiro capítulo acerca da Crise do liberalismo e nascimento do neoliberalismo. Eles destacam que o sistema em crise levou à revisão dos dogmas do liberalismo, originando como alternativas o "Novo liberalismo" e o "Neoliberalismo", cujo um dos pontos de tensão entre um tipo e outro, reside no fato de maior ou menor "[...] intervenção política em matéria econômica e social [...]" (p. 38).

Para pensar uma intervenção, significá-la e dar a ela novos limites, realizou-se a partir de 26 de agosto de 1938, em Paris, o Colóquio Walter Lippmann, encontro de cinco dias que reuniu expoentes da economia, tais como Friedrich Hayek, Jacques Rueff, Raymond Aron, Wilhelm Röpke, Alexander von Rüstow, dentre outros. Sendo o Colóquio a tônica do segundo capítulo da obra, os autores sublinham que nessa reunião internacional ficou clara a discordância entre os intelectuais, que se dividiam entre a corrente norte-americana "[...] fortemente influenciada pelos 'neoaustríacos' Friedrich Hayek e Ludwig von Mises e a corrente alemã [...]" (p. 73). Apesar da divergência entre os conservadores e os partidários de uma renovação do liberalismo, o objetivo maior era a busca por alternativas que salvaguardassem o modo de produção capitalista e aquilo que o mantém vigoroso, ou seja, as taxas de lucro.

Aspectos da corrente alemã são explorados no terceiro capítulo, $O$ ordoliberalismo entre "política econômica" e "política de sociedade”. Segundo os autores, “[...] o ordoliberalismo é a forma alemã do neoliberalismo [...]” (p. 101) e o uso daquele termo "[...] resulta da ênfase em comum desses teóricos na ordem constitucional e procedural que se encontra na base de uma sociedade e de uma economia de mercado". Por mais que haja variações nessa corrente o que faz com que, de um lado estejam os economistas e juristas da Escola de Freiburg, como Walter Eucken e Franz Böhm, e de outro, os liberais de inspiração sociológica Alfred MüllerArmack, Wilhelm Röpke e Alexander von Rüstow - os ordoliberais se preocupam em "[...] institucionalizar a economia de mercado na forma de uma 'constituição econômica', [...] de maneira a desenvolver a forma de mercado mais completa e mais coerente" (p. 112).

Diferente dos ordoliberais alemães, favoráveis a uma reinvenção do liberalismo, os neoliberais austro-americanos podem ser considerados mais conservadores em relação aos dogmas do laissez-faire, os quais são entendidos como "[...] fonte de prosperidade para todos e cada um" (p. 133), além de ser característica dessa corrente de intelectuais a "[...] valorização da concorrência e da empresa como forma geral da sociedade". Assim, no capítulo $O$ homem empresarial, os autores ressaltam como esse grupo de neoliberais valoriza a lógica da empresa para moldar os sujeitos, de modo que todos se tornem empreendedores, pois o empreendedorismo é uma "dimensão do homem", o que justifica o fato de a cultura da

\begin{tabular}{l|c|c|c|c|c}
\hline (c) Rev. Inter. Educ. Sup. & Campinas, SP & v.4 & n.3 & p.761-764 & set./dez. 2018
\end{tabular}


empresa e o espírito de empreendimento serem aprendidos desde a escola.

A lógica da empresa também está impregnada no Estado, dessa forma, longe de um Estado entendido como provedor de direitos, os neoliberais consideram-no "guardião do direito privado". Por isso, o quinto capítulo da obra versa sobre um Estado forte, cuja interferência está na direção de "[...] apenas velar pelo respeito às regras de conduta justa que são igualmente válidas para todos [...]” (p. 177).

A interferência política e econômica característica do Estado de bem-estar social entrou em colapso e com isso, na esteira de um cenário de crise, que envolvia uma inflação galopante, queda dos lucros e desaceleração do crescimento (p. 189), havia a necessidade de nova regulação do Estado e por consequência, novas configurações tanto para o político, quanto para o econômico. Nesse sentido, no sexto capítulo os autores abordam a Grande virada, período de uma política conservadora e neoliberal que marcou os anos 1980, cujos os nomes de Ronald Reagan e de Margaret Thatcher são símbolos. A "grande virada" se caracteriza pela "[...] implantação geral de uma lógica normativa [...]", que em termos do Estado, nas palavras de Dardot e Laval, não se trata de uma "simples retirada de cena", mas sim, "[...] um reengajamento político [...] sobre novas bases, novos métodos e novos objetivos" (p. 190).

Uma lógica normativa não deixa de existir também na corrente ordoliberal, apesar de o ordoliberalismo ser "[...] anterior à difusão da ideologia neoliberal nos anos 1970 e à crise de regulação do capitalismo fordista" (p. 245). Assim, no sétimo capítulo, os autores ponderam sobre As origens ordoliberais da construção da Europa, mostrando que a ideia de reformas, que implicam a flexibilização de salários, o sistema de aposentadorias e ainda, "a promoção do espírito de empreendimento", existem desde longa data, tendo em conta uma "economia social de mercado", cujos pilares são "[...] o princípio supremo da concorrência e a estabilidade dos preços, garantida por um Banco Central independente” (p. 250).

As regras de concorrência, portanto, são imprescindíveis para reger o Estado, segundo a ótica neoliberal. Desse modo, importa em grande medida uma reestruturação do Estado e uma "transformação da ação pública", sendo um desses aspectos as privatizações, as quais sinalizam o fim de um Estado produtor. Nesse sentido, no oitavo capítulo da obra os autores discutem $O$ governo empresarial, como ele se fortalece na sociedade, como a lógica da empresa invade o Estado, já que as regras de funcionamento do mercado concorrencial são importadas para o setor público (p. 274) e enfim, essa lógica da empresa também fortalece a instauração de um Estado avaliador e regulador.

Além de sua influência no Estado e na gestão, a lógica da empresa implica ainda, na fabricação do sujeito neoliberal, que é bem-sucedido, empoderado para cumprir seus objetivos e dentre outros aspectos, “[...] deve maximizar seus resultados, expondo-se a riscos e assumindo inteira responsabilidade por eventuais fracassos" (p. 328). O último capítulo da obra - A fábrica do sujeito neoliberal - evidencia, ao fim e ao cabo, uma "nova definição de

\begin{tabular}{l|l|l|l|l|l}
\hline (C) Rev. Inter. Educ. Sup. & Campinas, SP & v.4 & n.3 & p.761-764 & set./dez. 2018
\end{tabular}


homem" cunhada pela racionalidade neoliberal.

A obra A nova razão do mundo: ensaio sobre a sociedade neoliberal proporciona ao leitor entendimento de como o neoliberalismo se originou e se consolidou ao longo de um processo histórico, além de esclarecer que isso não foi simples, pois desde "as fraturas do liberalismo clássico" a partir de meados do século XIX, houve disputas e divergências entre intelectuais e economistas, fossem eles da corrente ordoliberal alemã ou então da neoaustríaca, acerca de qual seria a melhor alternativa para salvaguardar o modo de produção capitalista e sem dúvida, aumentar as taxas de lucro. Por isso, uma obra como essa de Dardot e Laval não pode deixar de ser lida, pois nesse momento histórico vemos o recrudescimento da relação capital $\mathrm{X}$ trabalho, a perda de direitos sociais e assim, ao considerarmos o influxo neoliberal, percebemos que essas são estratégias que fortalecem "a nova razão do mundo" e por conseguinte, o capitalismo.

\section{Sobre o Resenhista}

\section{${ }^{1}$ Aline Bettiolo dos Santos}

E-mail: bettiolo@ hotmail.com

Universidade do Oeste de Santa Catarina - Brasil

Mestranda do Programa de Pós Graduação em Educação da Universidade do Oeste de Santa Catarina (UNOESC) 